\title{
Torsion of gravid horn of bicornuate uterus: a rare case report
}

\section{Rama Singh Chundawat*, Radha Rastogi, Apoorva Tak}

Department of Obstetrics and Gynaecology, RNT Medical College, Udaipur, Rajasthan, India

Received: 25 April 2016

Accepted: 02 June 2016

*Correspondence:

Dr. Rama Singh Chundawat,

E-mail: drramasingh84@gmail.com

Copyright: (C) the author(s), publisher and licensee Medip Academy. This is an open-access article distributed under the terms of the Creative Commons Attribution Non-Commercial License, which permits unrestricted non-commercial use, distribution, and reproduction in any medium, provided the original work is properly cited.

\begin{abstract}
Torsion uterus is a rare complication of the third trimester of pregnancy. Etiological factors associated are myoma, mullerian anomalies, ovarian cyst, sudden change of lie of fetus and trauma. We report a rare case of levorotation of the gravid horn of bicornuate uterus leading to severe abruption and intrauterine death of the fetus. The case was managed by an emergency laparotomy with excision of the atonic gravid horn of bicornuate uterus. This is the third such case reported in the English literature as per our knowledge.
\end{abstract}

Keywords: Torsion uterus, Bicornuate uterus, Mullerian anomalies.

\section{INTRODUCTION}

Torsion uterus is defined as more than 45-degree rotation of uterus along its long axis. A slight degree of dextrorotation is fairly common in the third trimester of pregnancy. In $80 \%$ cases, an etiological factor is associated i.e. Myoma, mullerian anomalies, ovarian cyst, sudden change of lie of fetus and trauma. ${ }^{1}$ We report a rare case of levorotation of the gravid horn of bicornuate uterus by 180 degrees leading to severe abruption and intrauterine death of the fetus. This is the third such case reported in the English literature as per our knowledge.

\section{CASE REPORT}

22 years old G2P1 female presented to us with the complaints of amenorrhoea 7 months and severe abdominal pain. She had an uneventful term vaginal delivery 2 years back. On examination patient was very pale, pulse 120/min, BP 90/60 mm of $\mathrm{Hg}$, abdomen was distended, tense and extremely tender. Fundal height could not be delineated. Fetal heart sounds could not be localised. The per vaginal examination showed cervical os closed and no bleeding per vaginum. The size of the uterus could not be determined on per vaginal examination as bimanual examination was not possible due to the tense tender abdomen. An ultrasound done on the same day at a peripheral centre diagnosed it as the primary abdominal pregnancy of 28 weeks with a dead fetus and a non-gravid uterus. An emergency ultrasound at our centre revealed the same diagnosis.

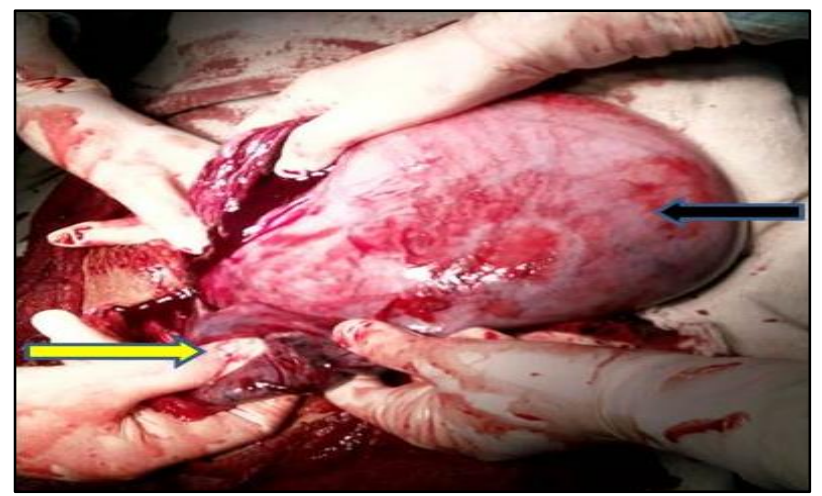

Figure 1: The torsion of gravid uterus (black marker) with congested ovary and tube (yellow marker).

As the patient was in shock we decided for an emergency laparotomy with primary abdominal pregnancy as our provisional diagnosis. The abdomen was opened by a lower midline incision. Severely congested uterus with dilated veins was seen. The congested ovary and tube were seen anteriorly on the left side indicating the torsion 
of gravid uterus $>180$ degrees (Figure 1). We tried to untwist the gravid uterus but were unsuccessful so we made a transverse incision on the posterior surface of the uterus and delivered a $900 \mathrm{gm}$ dead fetus. The placenta was completely separated and around $400 \mathrm{ml}$ of retro placental clots were removed.

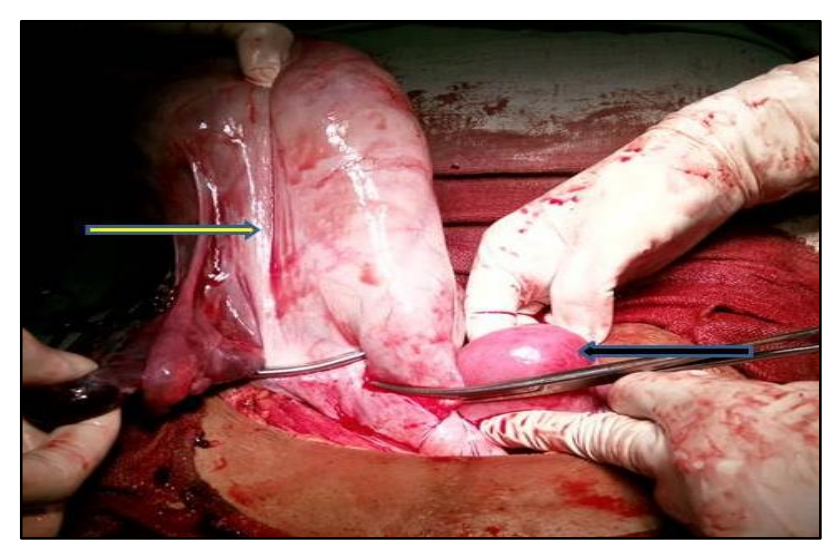

Figure 2: Atonic right sided gravid horn (yellow marker) and left sided non-gravid horn (black marker).

After the delivery of fetus and placenta, the uterus was exteriorized and de-rotated to its anatomical position. The non-gravid horn was seen so the diagnosis was now confirmed as 180 degree levorotation of the right horn of bicornuate uterus (Figure 2).

The atonic gravid horn did not respond to uterotonic drugs and so was excised. Two units of blood were transfused intraoperative. The postoperative period was uneventful and the patient was discharged on the postoperative fifth day.

\section{DISCUSSION}

Torsion uterus is a very rare complication of the third trimester of pregnancy. The etiological factors associated are myoma (31\%), mullerian anomalies (14.9\%), pelvic adhesion (8\%), ovarian cysts and changing fetal lie (longitudinal to transverse). In $16 \%$ cases, no etiological factor could be identified. ${ }^{1}$ In our case torsion occurred due to mullerian abnormality, i.e. bicornuate uterus. Most probably, the non-gravid horn of the bicornuate uterus rendered the uterus irregular predisposing it to torsion.

Medline search reveals that ours is the third case reported of torsion uterus due to the bicornuate uterus. Most of the other reported cases of torsion are due to myoma. U Jain and Agrawal SP reported a similar case of torsion uterus due to the bicornuate uterus. ${ }^{2}$ Jain $\mathrm{M}$ et al described a case of spontaneous rupture of the gravid horn of bicornuate uterus at 26 week due to levorotation of the uterus. $^{3}$

Review of literature shows that bicornuate uterus is also associated with another adverse pregnancy outcome like preterm labour, IUGR, a spontaneous rupture in the second trimester, obstructed labour due to the rudimentary horn, retained placenta and very rarely torsion of the gravid horn.

About two-third cases of torsion are dextrorotation and one-third is due to levorotation. In our case, there was levorotation of the right horn of bicornuate uterus. When rotation of uterus occurs initially the venous drainage is hampered leading to increased pressure in placental cotyledons causing an abruption. In severe cases when the uterine artery gets obliterated, fetal death is inevitable which was seen in our case.

The patient presentation in torsion uterus may be in a spectrum ranging from asymptomatic to mild abdominal pain and cramping to shock and maternal death. According to Jensen et al, the main clinical features are severe abdominal pain, vaginal bleeding, obstructed labour, urinary or intestinal symptoms. ${ }^{4}$ There is no specific symptom complex associated with torsion. Therefore, torsion uterus should always be kept in the differential diagnosis of acute abdomen in pregnancy especially if associated with myoma, bicornuate uterus, and other predisposing factors.

Torsion can be confused with primary abdominal pregnancy and only in some sonography may allow correct identification as what happened in our case. Antenatal diagnosis by USG and colour doppler is possible by observing a change in location of the placenta. ${ }^{5}$ Dietz et al and Nicholson et al have suggested the accuracy of diagnosing torsion by $\mathrm{X}$ sign on MRI. The vagina is normally seen as an $\mathrm{H}$-shaped structure on MRI. But with torsion of uterus and vagina, it appears as X-shaped structure. ${ }^{6}$ The acuteness and rarity of this condition limit the use of MRI, therefore, diagnosis of torsion is made mostly at the time of laparotomy.

The management of torsion uterus is laparotomy. In torsion uterus, >180-degree inability to identify the bladder flap, dilated veins on the lower segment and excessively stretched round ligament should raise the suspicion of torsion to avoid inadvertent posterior hysterotomy incision. The routine practice of palpating round ligament at the time of caesarean section would most likely prevent inadvertent hysterotomy at the sites other than anterior lower segment According to literature, many times it is not possible to derotate the uterus with fetus and placenta in situ so a deliberate posterior low transverse is given which may be associated with increased risk of injury to uterine vessels and urethra. Elective caesarean has to be done in future pregnancy as rupture rate is not known in such type of incision.

\section{CONCLUSION}

The possibility of torsion uterus should always be considered in managing an acute abdomen in the third trimester of pregnancy, especially if associated with 
predisposing factors like myoma and bicornuate uterus. In the case of posterior hysterotomy incision, elective caesarean has to be done in a future pregnancy as rupture rate is not known in such type of incision.

Funding: No funding sources

Conflict of interest: None declared

Ethical approval: Not required

\section{REFERENCES}

1. Marshall LM, Spiegelman D, Barbieri RL, Goldman MB, Manson JE, Colditz GA, et al. Variation in the incidence of uterine leiomyoma among premenopausal women by age and race. Obstet Gynecol. 1997;90:967-73.
2. Jain U, Agarwal SP. Torsion of gravid horn of bicornuate uterus. Journal of the Indian Medical Association. 1986;84:222-8.

3. Jain M, Tripathi R, Jain S, Verma A, Bajpai N. Spontaneous rupture of bicornuat uterus caused by levorotation due to congenital band. Nepal Journal of Obstetrics and Gynaecology. 2013;8:57-9.

4. Jensen JG. Uterine torsion in pregnancy. Acta Obstetricia at gynecologica Scandiavia. 1992;71:260-5.

5. Sherer DM, Smith SA, Sanko SR. Uterine sacculation sonographically mimicking an abdominal pregnancy at 20 weeks gestation. Am J Perinatology. 1994;11:350.

6. Nicholson WK, Coulson CC, Mc Coy MC. Pelvic MRI in evaluation of uterine torsion. Obstetrics and gynaecology. 1995;85(5):888-90.

Cite this article as: Chundawat RS, Rastogi R, Tak A. Torsion of gravid horn of bicornuate uterus: a rare case report. Int J Reprod Contracept Obstet Gynecol 2016;5:2428-30. 